\title{
Surface mapping of RS-T segment in acute myocardial infarction
}

\author{
D. S. Reid, L. J. Pelides ${ }^{1}$, and J. P. Shillingford \\ From M.R.C. Cardiovascular Unit and Department of Medicine, Hammersmith Hospital, \\ London W.I2
}

\begin{abstract}
$A$ method of surface mapping of the RS-T segment deviations that occur in acute myocardial infarction is described. The results observed in 15 patients are recorded and the potential value of this procedure is discussed in (i) diagnosis of myocardial infarction; (ii) delineating the extent of the myocardial ischaemia; and particularly (iii) its use as a method of examining the effect of therapies on the extent of myocardial ischaemia.
\end{abstract}

Body surface iso-potential maps of the QRS have been reported in normal adults (Taccardi, 1963), children (Spach et al., I966), and infants (Tazawa and Yoshimoto, 1969), and in a number of cardiac disorders (Blumenschein et al., 1968; Karsh, Spach, and Barr, 1970). In experimental myocardial infarction in dogs, the area of the RS-T segment deviation in the epicardial leads has been used to represent the area of ischaemic myocardium (Rakita et al., 1954; Katcher, Peirce, and Sayen, 1960; Sayen et al., 1958; Braunwald et al., 1969). It seemed probable that in man surface mapping of the RS-T segment deviations on the chest wall would reflect in some measure the underlying epicardial changes and perhaps define the position and extent of the myocardial infarction to a greater degree than the routine electrocardiogram.

It is the purpose of this paper to describe a method and give the results of surface mapping of the RS-T segment deviations that were observed in a series of cases of proven myocardial infarction.

\section{Methods}

Fifteen patients who were admitted to the coronary care unit in the Hammersmith Hospital with a clinical diagnosis of acute myocardial infarction were studied. All but one had electrocardiographic evidence of acute myocardial infarction on the standard I4 lead electrocardiogram (including $\mathrm{V}_{4} \mathrm{R}$ and $\mathrm{V}_{7}$ ) and all had a transient diagnostic rise in serum enzymes.

Electrocardiograms were recorded using a direct writing ink jet apparatus (Mingograph Elema-Schonander) recording on the three channels simultaneously. The electrodes used were

Received 12 October 1970.

1 Commonwealth Medical Scholar. the Welsh self-retained type with a contact diameter of $\mathbf{I ~ c m}$. In order to avoid spread of potentials the electrode jelly was applied only over a small area and the electrodes were carefully separated. The gain employed was $10 \mathrm{~mm}$ for $\mathrm{I} \mathrm{m}$ volt and the paper speed was $25 \mathrm{~mm} / \mathrm{sec}$.

The praecordial electrocardiograms used for surface mapping were recorded with the patient in the supine position and recorded daily for the first 7 days after the onset of symptoms and subsequently every few days during the patient's stay in hospital. In a few patients further electrocardiograms were recorded from 2 to 7 weeks later. These electrocardiograms were recorded from 72 points, distributed evenly throughout an area which extended from the mid-clavicular line on the right to the mid-axillary line on the left and from a line drawn horizontally through the angle of Louis to a line drawn horizontally through a point $6 \mathrm{~cm}$ below the xiphisternum (Fig. I). These points, which were 3 to $4 \mathrm{~cm}$ apart, were marked with a skin pencil so that all subsequent electrocardiograms were obtained from the same points. A standard electrocardiogram was recorded immediately before the praecordial electrocardiogram on each occasion.

The RS-T segment deviations were measured using the TP segment as the isoelectric line, or the PQ segment when the TP segment was difficult to locate because of tachycardia. The RS-T segment deviation was measured in $\mathrm{mm}$ to the nearest $0.5 \mathrm{~mm}$ at $0.06 \mathrm{sec}$ after the nadir of the $S$ wave.

The RS-T segment deviations obtained by this method were then recorded on a standard diagram on which the 72 points were represented at $\mathrm{I} \mathrm{cm}$ intervals. Isopotential lines were drawn on the map by joining points of equal magnitude and by interpolating when this was necessary. The surface maps produced in this way showed the area of maximum RS-T segment elevation and the area over which there was RS-T segment elevation or depression. 


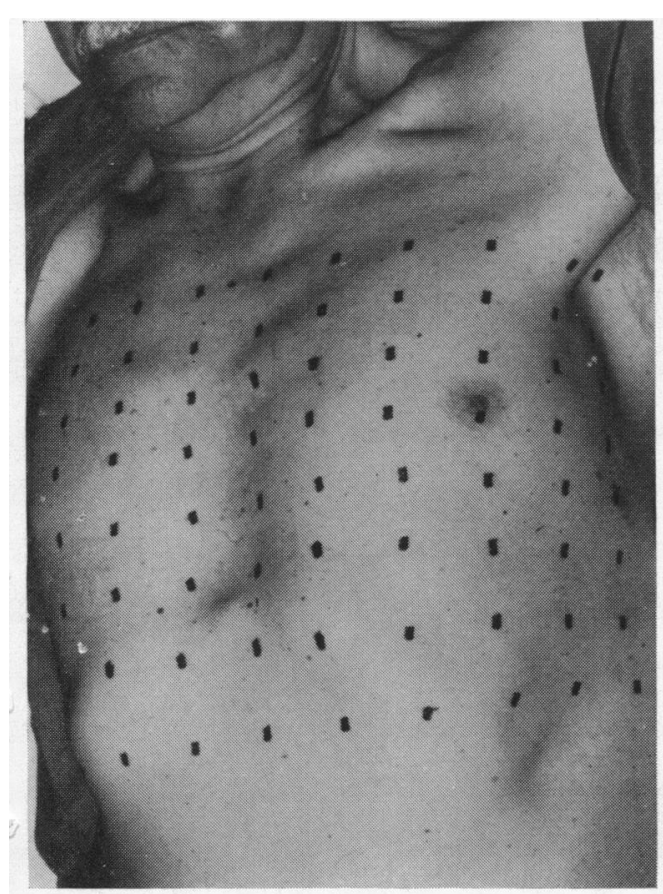

FIG. I Position and distribution of the recording points on the surface of the chest.

\section{Results}

In the 15 patients studied, 8 had anterior, 5 had inferior myocardial infarctions, and $\mathrm{I}$ had a lateral myocardial infarction on the standard , electrocardiogram. One patient had no evidence of myocardial infarction on the standard electrocardiogram despite characteristic clini$\mathrm{cal}$ and biochemical features.

Anterior myocardial infarction The 8 patients with anterior myocardial infarction had similar patterns on the surface maps. In all there was an area of maximum RS-T seg- ment elevation surrounded by an area of lesser RS-T segment elevation (Fig. 2 and 3). The area of RS-T segment elevation varied considerably from an area enclosing three points

" on the surface map to one that involved nearly the whole surface map. The maximum height

of the RS-T segment elevation varied from $2.5 \mathrm{~mm}$ to $10 \mathrm{~mm}$ and there was also a considerable variation in the rate of resolution of the surface maps. In 3 of the cases there was no RS-T segment elevation above $2 \mathrm{~mm}$ at 5 , * IO, and 15 days respectively after the onset of symptoms, while in 2 others measured at

- 38 and 47 days there was still a large area of RS RS-T segment elevation above $2 \mathrm{~mm}$.

Inferior myocardial infarction Of the 5 patients with inferior myocardial infarction, 4
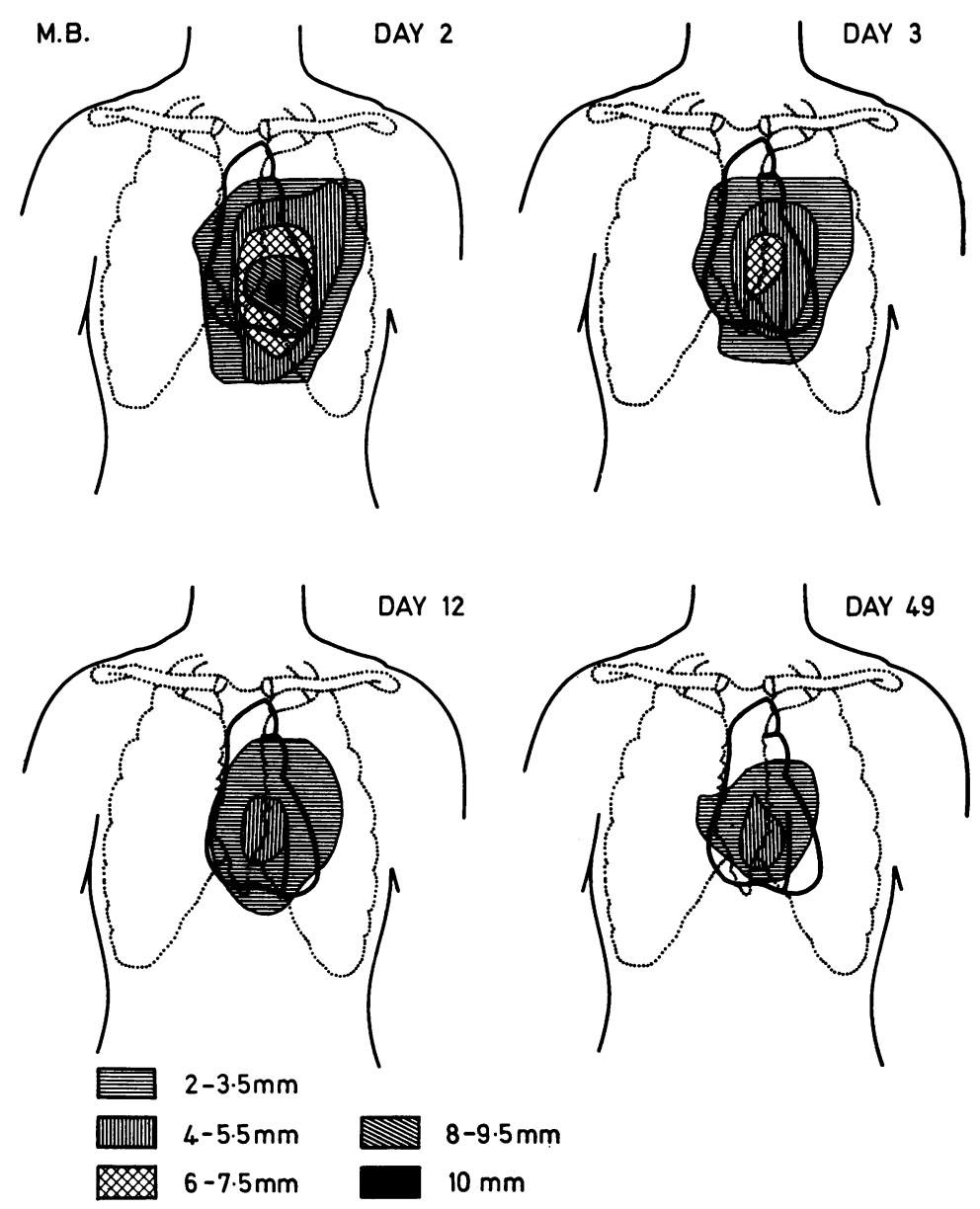

FIG. 2 Anterior myocardial infarction with persistent $R S-T$ elevation.

had similar surface maps with RS-T segment elevation of a variable size in the lower part of the map associated with RS-T segment depression covering a wide area of the upper part of the surface map (Fig. 4). The area of RS-T segment depression in the upper part of the surface map is probably a reflection of a larger area of RS-T segment elevation which is not recorded because of the position of the ischaemic tissue.

The other patient who had an inferior myocardial infarction on the standard electrocardiogram did not show this pattern. This patient had a ventricular aneurysm diagnosed by clinical and radiological means and by apex cardiography, and it seems probable that this altered the surface map by causing persistent RS-T elevation. This patient was also on digoxin which could also alter the surface map by causing RS-T segment depression. 
Lateral infarction In this patient a small area of the RS-T segment elevation appeared transiently on the lateral aspects of the surface map (Fig. 5).

Normal electrocardiogram In this patient who had a classical history of myocardial infarction associated with a rise in enzymes (CPK 700 units, LDH 385 units $(70 \%$ heat stable) and SGOT 92 units), and a normal standard electrocardiogram, the surface map initially showed a small area of RS-T segment elevation over the lateral part of the map which later increased in size and was associated with an area of RS-T segment depression on the upper part of the map (Fig. 6). These features suggest that a lateral myocardial infarction had occurred and that there was also inferior myocardial damage causing the RS-T segment depression on the upper part of the map.

\section{Discussion}

In this study 72 explored points were used. This number was selected as the most easily manageable number that would cover as many points within the selected area for study. It may be that for more accurate delineation of the area of the ischaemia, more records could be obtained over the area of ischaemia after it had been located on the chest surface.

The RS-T segment deviations that occur in acute myocardial infarction are partly due to a current of injury which deviates the $T-Q$ segment and partly due to changes in the rate of repolarization of the ischaemic muscle which causes true RS-T segment deviation (Samson and Scher, I960). However, the capacitor-coupled electrocardiograph compensates for the injury current so that $T-Q$ segment deviation and the true RS-T segment deviations are summated to give a total RS-T segment deviation which can be measured using the T-P segment as the base line.

The magnitude of the RS-T segment deviations was measured at $0.06 \mathrm{sec}$ after the nadir of the $S$ wave. It has been shown that this is the most reliable point to measure the RS-T segment deviations that occur on exercise, as it is the point that is least affected by the $S$ and $T$ waves as well as by the random artefacts that are obtained on the exercise electrocardiogram (Bruce et al., 1966). It is likely too that this point is beyond the site of atrial repolarization and any effect that this might have on the RS-T segment deviation will be avoided.

Wilson and his associates have succeeded in demarcating the boundaries of experimental myocardial infarction in animals using the
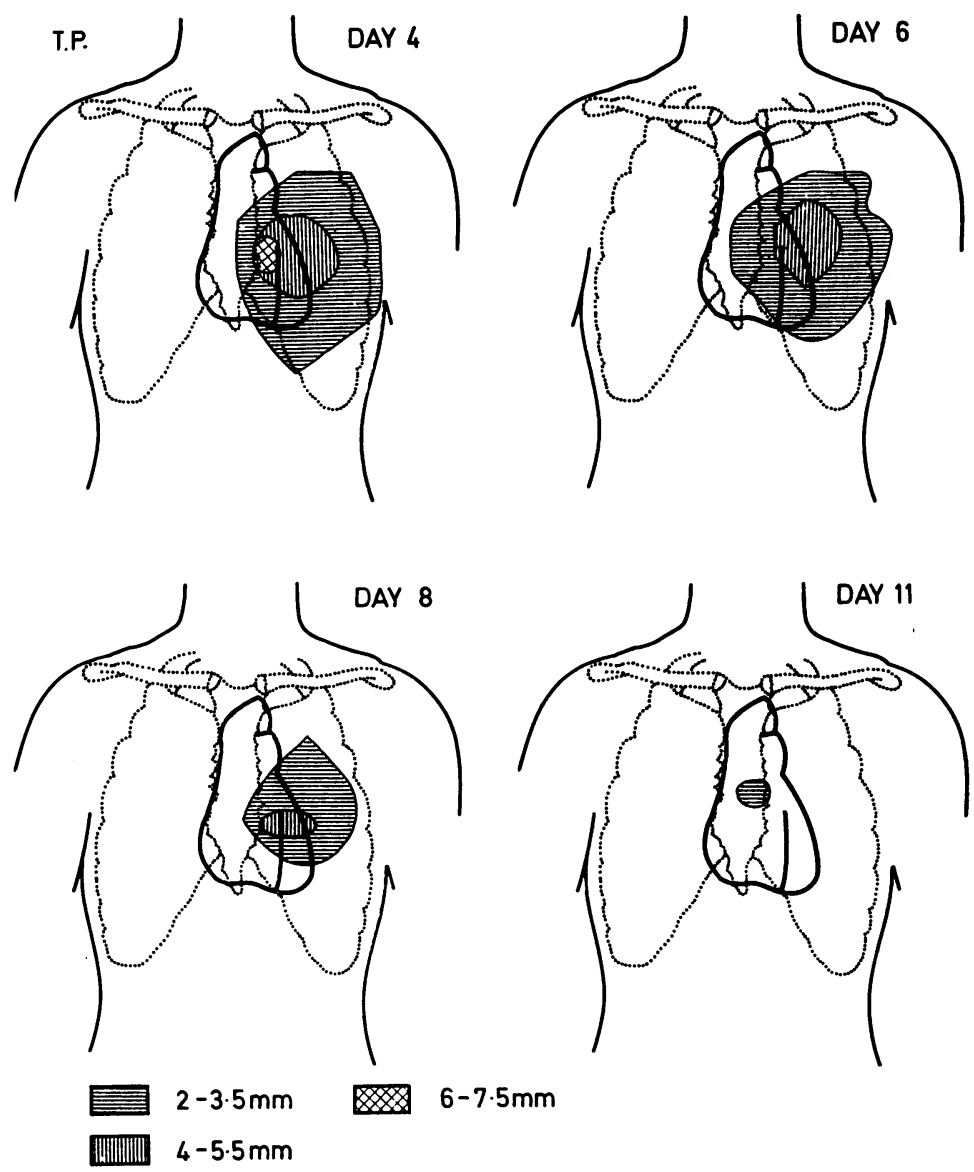

FIG. 3 Anterior myocardial infarction. By day II the area of RS-T segment elevation is small in contrast to Fig. 2.

alteration in the QRS-T that occurred in the epicardial leads over the ischaemic muscle (Wilson, Johnston, and Hill, 1935; Johnston, Hill, and Wilson, 1935). As it is generally accepted that the RS-T segment deviations that occur in acute myocardial infarction arise from injured tissue as a result of alteration in its repolarization, the RS-T segments alone could be used to delineate the area of ischaemic tissue. Braunwald and his colleagues recording from epicardial leads have in fact used the RS-T segment shifts that occur in experimental myocardial infarction to study alteration in the area of ischaemic tissue (Braunwald et al., 1969). However, epicardial leads cannot be totally equated with praecordial leads. Thus the location and magnitude of the RS-T segment deviations recorded with praecordial leads depend not only on the site of the ischaemic area but also on the position of the heart within the chest, the distance of the exploring electrodes from the ischaemic 
area, and the resistance of the tissue through which the potential has to travel. In addition, the precise boundaries of the area of ischaemia as projected onto the surface of the chest will not be as clear cut as those obtained from epicardial leads, because the leads recording from the periphery of the ischaemic area will be influenced both by the ischaemic tissue and by the normal myocardium. However, accepting these limitations the surface maps probably reflect, in an individual, the area of the ischaemic tissue. It is, therefore, suggested that the surface maps obtained in this manner could be used to study the rate of healing, the presence of extension, and the effects of therapies on the ischaemic myocardium in individual patients.

This study has shown that distinctive maps - can be obtained for different areas of ischaemia. As it is well established that the standard electrocardiogram can be normal in acute myocardial infarction (Johnson et al., 1959)

- and that there may be delay in appearance of the electrocardiographic features of acute

myocardial infarction (Short, I968, I970), it is likely that the surface mapping of the RS-T

* segment will be of value in diagnosing cases of myocardial infarction with a normal standard electrocardiogram. The reason that recording > over a wider area may reveal an undiagnosed infarct is that in some cases the site of the

- infarction may be in a position that is inaccessible to the standard electrocardiogram.

"In I patient in this series of I5 patients, the surface map revealed an ischaemic area in the presence of a normal standard electrocardiogram. Furthermore, the pattern obtained in the surface maps from the patients with - inferior myocardial infarctions in this series suggests that the electrocardiogram obtained

- from the lower and upper chest may reveal inferior myocardial infarctions when the standard electrocardiogram is normal.

We wish to express thanks to Miss J. Powell for the diagrams.

\section{- References}

Blumenschein, S. D., Spach, M. S., Boineau, J. P.,

- Barr, R. C., Gallie, T. M., Wallace, A. G., and Ebert, P. A. (1968). Genesis of body surface potentials in varying types of right ventricular hypertrophy. Circulation, 38, 917.

Braunwald, E., Covell, J. W., Maroko, P. R., and Ross, J. (1969). Effects of drugs and of counterpulsation on myocardial oxygen consumption:

- observations on the ischemic heart. Circulation, 39-40, Suppl. 4, p. 220.

Bruce, R. A., Mazzarella, J. A., Jordan, J. W., and Green, E. (1966). Quantitation of QRS and ST segment responses to exercise. American Heart fournal, 71, 455.
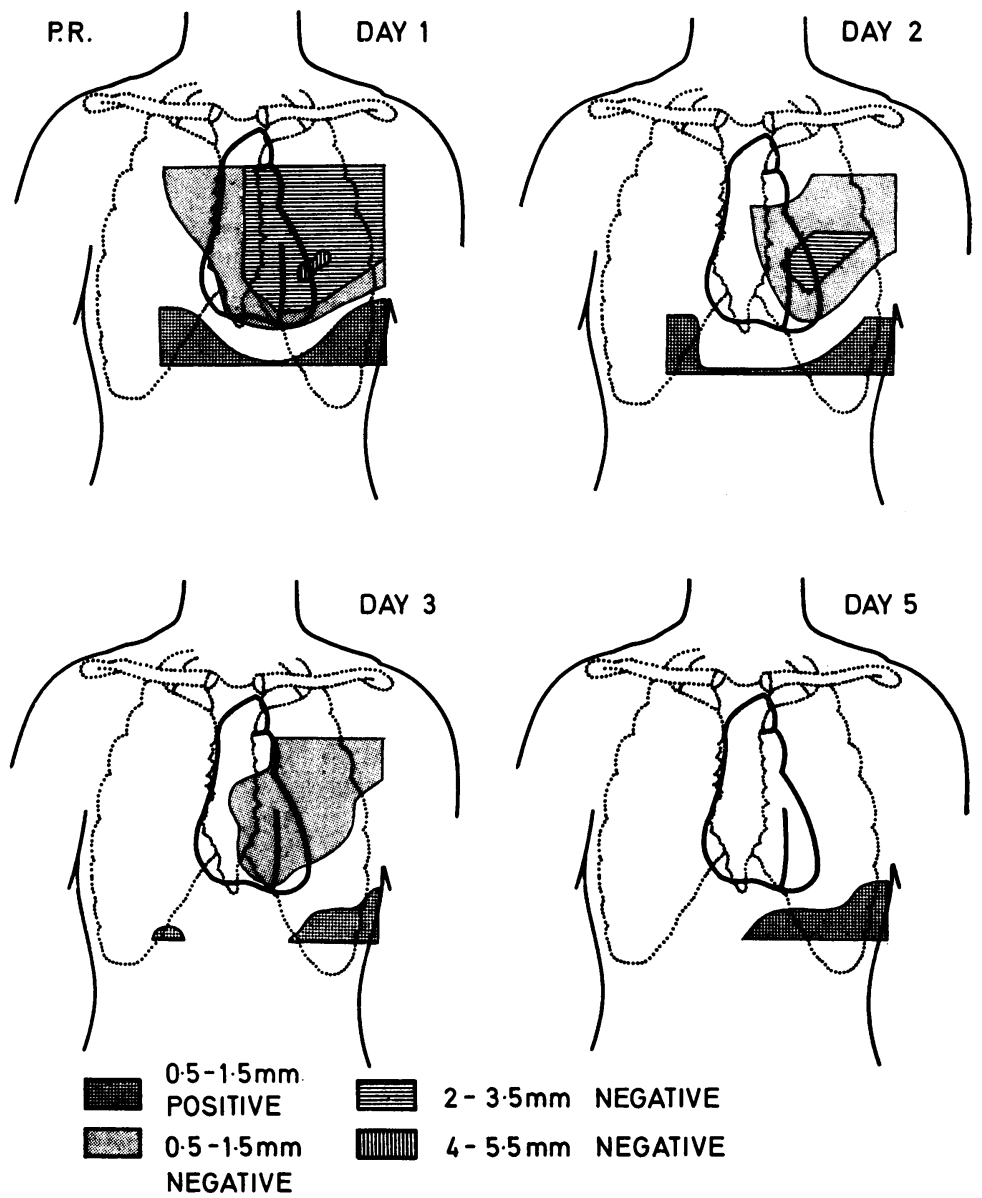

FIG. 4 Inferior myocardial infarction. The elevation seen at day 5 persisted until day II. $A$ subsequent map obtained on day 40 showed that this area was no longer present.

\section{FIG. 5 Lateral myocardial infarction.}

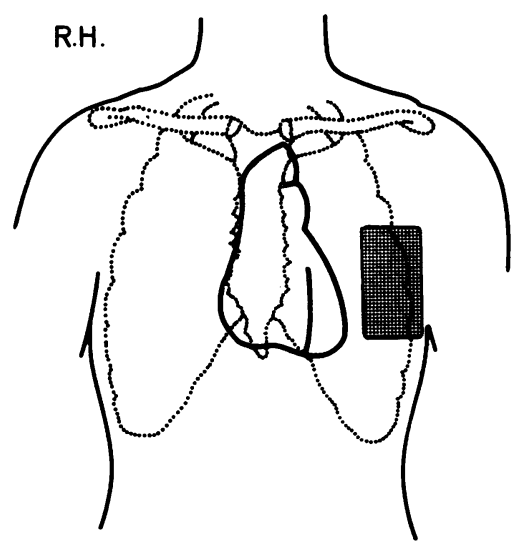

0.5-1.5mm POSITIVE 
Johnson, W. J., Achor, R. W. P., Burchell, H. B., and Edwards, J. E. (1959). Unrecognized myocardial infarction. A clinicopathologic study. Archives of Internal Medicine, 103, 253.

Johnston, F. D., Hill, I. G. W., and Wilson, F. W. (1935). The form of the electrocardiogram in experimental myocardial infarction. II. The early effects produced by ligation of the anterior descending branch of the left coronary artery. American Heart fournal, 10, 889.

Karsh, R. B., Spach, M. S., and Barr, R. C. (1970). Interpretation of isopotential surface maps in patients with ostium primum and secundum atrial defects. Circulation, 41, 913.

Katcher, A. H., Peirce, G., and Sayen, J. J. (1960). Effects of experimental regional ischemia and levarterenol on the RS-T segment and baseline of ventricular surface electrocardiograms obtained by direct coupled amplification. Circulation Research, 8, 29.

Rakita, L., Borduas, J. L., Rothman, S., and Prinzmetal, M. (1954). Studies on the mechanism of ventricular activity. XII. Early changes in the RS-T segment and QRS complex following acute coronary artery occlusion: experimental study and clini$\mathrm{cal}$ applications. American Heart fournal, 48, 35I.

Samson, W. E., and Scher, A. M. (1960). Mechanisms of S-T segment alteration during acute myocardial injury. Circulation Research, 8, 780.

Sayen, J. J., Sheldon, W. F., Peirce, G., and Kuo, P. T. (1958). Polarographic oxygen, the epicardial electrocardiogram and muscle contraction in experimental acute regional ischaemia of the left ventricle. Cirulation Research, 6, 779.

Short, D. (1968). Value and limitations of electrocardiogram in diagnosis of slight and subacute coronary attacks. British Medical fournal, 4, 673.

Short, D. (1970). The earliest electrocardiographic evidence of myocardial infarction. British Heart fournal, 32, 6.

Spach, M. S., Silberberg, W. P., Boineau, J. P., Barr, R. C., Long, E. C., Gallie, T. M., Gabor, J. B., and Wallace, A. G. (1966). Body surface isopotential maps in normal children, ages 4 to 14 years. American Heart fournal, 72, 640.

Taccardi, B. (1963). Distribution of heart potentials on the thoracic surface of normal human subjects. Circulation Research, 12, 341.

Tazawa, H., and Yoshimoto, C. (1969). Electrocardiographic potential distributions in newborn infants from twelve hours to eight days after birth. American Heart fournal, 78, 292.

Wilson, F. N., Johnston, F. D., and Hill, I. G. W. (1935). The form of the electrocardiogram in experimental myocardial infarction. IV. Additional observations on the later effects produced by ligation of the anterior descending branch of the left coronary artery. American Heart fournal, 10, 1025.
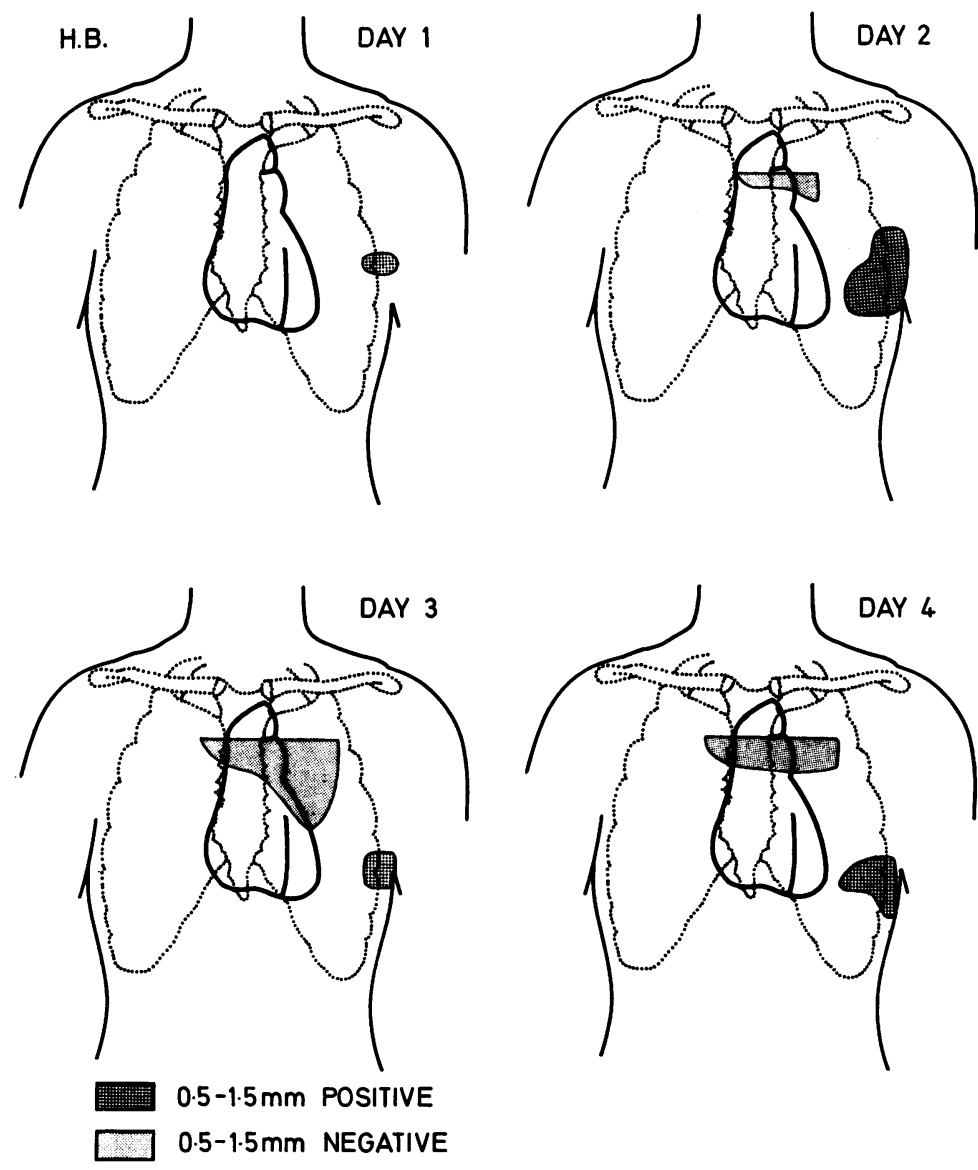

FIG. 6 Normal electrocardiogram. Transient

$R S-T$ segment elevation and depression seen with no $R S-T$ segment changes present on

day 7. 